SHORT COMMUNICATION

\title{
Studies on the carotenoids of jakfruit (Artocarpus heterophyllus Lam.) from Matale and Kurunegala Districts
}

\author{
A.M. Buddhika Priyadarshani ${ }^{1 *}$, E.R. Jansz ${ }^{2}$ and H. Peiris ${ }^{1}$ \\ 1 Department of Biochemistry, Faculty of Medical Sciences, University of Sri Jayewardenepura, Gangodawila, Nugegoda. \\ 2 29/1, Pietersz Place, Nugegoda.
}

Revised: 12 March 2007 ; Accepted: 21 May 2007

\begin{abstract}
The kernels of ripe jakfruit (Artocarpus heterophyllus Lam.) (Sinhala: waraka) is widely consumed in Sri Lanka. Specimens were collected from Kurunegala and Matale Districts. The yellow fruit kernels were found to contain carotenoids. The variations from specimen to specimen were manifest not only in total content but also in components. $\beta$-Carotene varied from traces to $50, \alpha$-carotene from traces to 20.5 , lutein from 2.7 to $221.5 \mu \mathrm{g}$. $100^{-1} \mathrm{~g}$ of dry weight (DW). A range of contents was also shown in unidentified fractions. Retinol equivalent (RE) and retinol activity equivalent (RAE) varied from traces to 10 and $5 / 100 \mathrm{~g} \mathrm{DW}$, respectively. The major compounds common to all samples in the saponified petroleum ether extract were lutein and unidentified fraction II as determined by Open Column Chromatography (OCC), Reverse Phase High Performance Liquid Chromatography (RPHPLC), Thin Layer Chromatography (TLC) and chemical tests. A carboxylic acid carotenoid was extracted into the alkaline water layer after saponification and tentatively identified by its chemical characteristics and spectrum as crocetin. In vitro bioaccessibility was low $(\sim 8 \%)$ probably due to the rubbery texture of the kernel.
\end{abstract}

Key words: Artocarpus heterophyllus, carotenoids, in vitro bioaccessibility, jakfruit, retinol equivalent

\section{INTRODUCTION}

Different pro-vitamin A sources have the potential to alleviate to varying extents, the deficiency of vitamin A in Sri Lanka ${ }^{1}$. Carotenoids of ripe jakfruit (Artocarpus heterophyllus) kernel have been studied before and reportedly had a retinol equivalent (RE) of $141.6 / 100 \mathrm{~g}$ dry weight $(\mathrm{DW})^{2}$. This study also showed that the coefficients of variation of the components ranged from 4.8 to $9.7 \% \%^{2}$, which appears to be low. Crocetin has been identified in the saponified petroleum ether extract. This is not possible as it is a dicarboxylic acid. The $R_{f}$ value of crocetin in two reports of the same analysis has been given as $0.33^{2}$ and $0^{3}$. There was therefore ample justification for ripe jakfruit kernel to be studied in more detail.

The main objectives of the study are to determine carotenoid profile of ripe jakfruit kernel collected from the Kurunegala and Matale Districts and estimating the in vitro bioaccesibility of ripe jakfruit kernel taking cognizance of the fact that its inherent texture could be an impediment to disintegration in the gastrointestinal tract. Minor objectives included: a study of crocetin, and determining the effect of heat $\left(121^{\circ} \mathrm{C}\right)$ on carotenoids of the kernel.

\section{METHODS AND MATERIALS}

Raw material: Mature jakfruits (A. heterophyllus Lam) (variety:waraka) were collected from 1.Dambagahamula, 2.Dembawa, 3.Wegodapola, 4.Kanandana, 5.Maussawa and 6.Omaragolla of Kurunegala and Matale Districts. The fruits showed the normal variations in shape, size and texture of pericarp. On ripening (1-5 d), as judged by the softening of the pericarp and characteristic odour and colour, the fruit was cut open and the bulbs were removed. The number of bulbs varied from 55 to 162 . Specimen No: 5 had thin, long, light coloured bulbs. 20 bulbs were randomly selected, de-seeded and cut into pieces of about $5 \times 5 \mathrm{~mm}$ and mixed thoroughly. From this homogeneous mixture 10-20 g (depending on the colour intensity) were used for the extraction of carotenoids. In this study one fruit was analysed from each location.

Extraction of carotenoids was done as described previously ${ }^{5}$. $\beta$-Apo- 8 '-carotenal (trans) was employed as an internal standard. As the water layer showed a yellow colour on partition into petroleum ether (BP, $\left.40-60{ }^{\circ} \mathrm{C}\right)$,

\footnotetext{
${ }^{*}$ Corresponding author
} 
this step was repeated with increased concentration of diethyl ether $(10 \%)$. The extract was saponified using $10 \%$ methanolic $\mathrm{KOH}^{4}$ because fatty acid esters of carotenoids were present as indicated by Open Column Chromatography (OCC) and High Performance Liquid Chromatography (HPLC) of the unsaponified sample. The sample was concentrated by nitrogen flushing and subject to OCC. The alkaline water extract of the saponification washing was used for isolation of crocetin. OCC, identification and HPLC were carried out as previously described $^{5}$.

In-vitro bioaccessibility: This was carried out as described previously ${ }^{6}$ with specimen No:1 (given in Table 1). Jakfruit kernel was cut up into pieces of $9 \times 9$ $\mathrm{mm}$ (as determined by a panel masticating jakfruit) and pounded to mimic action by teeth. In a further procedure each member of the panel masticated and re-gurgitated a jakfruit kernel for in vitro bioaccessibility studies.

Isolation and methylation of crocetin: The water extract from saponification was adjusted to $\mathrm{pH} 2$ and extracted with petroleum ether. The spectrum of the extract was scanned with a double beam spectrophotometer. As the extract appeared to be impure with ultraviolet absorbing impurities, it was subjected to OCC and TLC as in the case of petroleum ether extract. The crocetin in methanol was dried with anhydrous $\mathrm{Na}_{2} \mathrm{SO}_{4}$ for $24 \mathrm{~h}$ and two drops of concentrated $\mathrm{H}_{2} \mathrm{SO}_{4}$ was added and kept at room temperature $\left(27^{\circ} \mathrm{C}\right)$ for $24 \mathrm{~h}$. TLC was carried out using the solvent system mentioned above. Procedures for carotenoid extraction and identification were carried out in dim light and away from oxygen (except TLC). Storage was done under nitrogen at $-20{ }^{\circ} \mathrm{C}$. Solvent evaporation was done by nitrogen flushing.

Effect of autoclaving: Jakfruit kernel (specimen No:1 which contained the highest pro-vitamin A carotenoid content) was autoclaved (STURDY SA - 232) in a sealed container for $20 \mathrm{~min}$ at $1.3 \mathrm{~kg} / \mathrm{cm}^{2}\left(121^{\circ} \mathrm{C}\right)$. Extraction and HPLC analysis were carried out as described previously.

Retinol equivalent (RE) and retinol activity equivalent (RAE): RE was calculated according to the conversion factors; $6 \mu \mathrm{g}$ of $\beta$-carotene and $12 \mu \mathrm{g}$ of $\alpha$-carotene to give $1 \mu \mathrm{g}$ of retinol $(1 \mathrm{RE})^{7}$ and RAE was calculated according to the conversion factors; $12 \mu \mathrm{g}$ of $\beta$-carotene and $24 \mu \mathrm{g}$ of $\alpha$-carotene to give $1 \mu \mathrm{g}$ of retinol (1 RAE) $)^{8}$.

Determination of moisture content: Moisture determination was done by freeze-drying (1g) in triplicate to constant weight.

\section{RESULTS}

\section{Carotenoid composition and retinol equivalent}

The carotenoids identified from ripe jakfruit kernels were $\beta$-carotene, $\alpha$-carotene, lutein, $\alpha$-zeacarotene, unidentified I (trans form), II (cis and trans forms), III (cis form) and IV (trans form). In most specimens lutein was the main contributor to the total carotenoid content. Among the unidentified carotenoids, all were epoxy carotenoids except for unidentified fraction I and according to chromatographic properties they were polar carotenoids. $\alpha$-Zeacarotene was detected from OCC but as its concentration was very low it was not detected by HPLC at $450 \mathrm{~nm}$ ( $\lambda_{\text {max }}$ of $\alpha$-zeacarotene is $421 \mathrm{~nm})$. All the carotenoids showed a marked variation in their content from specimen to specimen. Unidentified fractions III and IV were found only in specimen No: 5 and 6 relatively in large amounts. Table 1 shows the vast variation in content, profile, RE and RAE.

\section{In vitro bioaccessibility}

In vitro bioaccesssibility is very low (8\%). On inclusion of in vivo mastication prior to the in vitro digestion, bioaccessibility ranged from $12 \%$ to $18 \%$. This may be due to differences in the mastication process among individuals and therefore has to be repeated using a large number of individuals.

\section{Effect of heat}

On autoclaving, the carotenoid content decreased to trace amounts with some changes to the carotenoid profile. Extensive splitting of the $\beta$-carotene peak indicated considerable isomerisation. After autoclaving a new unidentified carotenoid was released into the water medium. Characteristics of this carotenoid were as follows; $\lambda_{\max }=420,440$ and 468, di-epoxy, trans with the $\mathrm{R}_{\mathrm{f}}$ values of 0.21 on an activated TLC plate.

\section{Crocetin}

As crocetin is a dicarboxylic acid it is expected in the water layer after saponification with methanolic $\mathrm{KOH}$. After acidification to $\mathrm{pH} \mathrm{2,} \mathrm{the} \mathrm{yellow} \mathrm{coloured} \mathrm{extact}$ gave a spectrum with petroleum ether at 398, 420 and $442 \mathrm{~nm}\left(\lambda_{\max }\right.$ for all trans form $400,422,450 \mathrm{~nm}$ in petroleum ether) $)^{4}$ with spectral fine structure of 50 and $\mathrm{R}_{\mathrm{f}}$ value of 0.09 on an activated TLC plate. On attempted methylation with $\mathrm{H}_{2} \mathrm{SO}_{4}$ the yellow colour was lost as $\mathrm{H}_{2} \mathrm{SO}_{4}$ reacts with double bonds conjugated to $(\mathrm{COOH})$ carbonyl groups and the solution was colourless and no carotenoid peaks were observed in the $u v / v i s$ spectrum. 


\section{Acknowledgement}

IPICS grant SRI: 07 is gratefully acknowledged for financial assistance.

\section{References}

1. Medical Research Institute, Sri Lanka. (1998). Report of the survey on vitamin A deficiency status of children in Sri Lanka 1995/96 Publ. UNICEF.

2. Chandrika U.G., Jansz E.R. \& Warnasuriya N.D. (2005). Analysis of carotenoids in ripe jackfruit (Artocarpus heterophyllus) kernel and study of their bioconversion in rats. Journal of the Science of Food and Agriculture 85: 186-190.

3. Chandrika U.G. (2004). Content, bioavailability, bioconversion and antioxidant activity of carotenoids of some Sri Lankan fruits and green leafy vegetables. Ph.D. thesis, University of Sri Jayewardenepura.

4. Rodriguez-Amaya D.B. (1999). A Guide to carotenoid analysis in foods. ILSI press, Washington.

5. Priyadarshani A.M.B. \& Jansz E.R. (2006). The effect of maturity and in vitro bioaccessibility after cooking on carotenoids of Lasia spinosa stem. Journal of National Science Foundation Sri Lanka. 34: 131-136.

6. Hedrèn E., Diaz V. \& Svanberg U. (2002). Estimation of carotenoid accessibility from carrots determined by an in-vitro digestion method. European Journal of Clinical Nutrition 56:425-430.

7. Food and Agricultural Organisation. (1988). Requirements of vitamin $A$, iron, folate, and vitamin $B_{12}$ : Report of a joint FAO/WHO Expert Consultation, Rome, Italy.

8. Hedren E. (2004). In vitro accessibility of provitamin A carotenoids in vegetables and fruits. Ph.D. thesis. University of Chalmers, Sweden.

9. Priyadarshani A.M.B. \& Chandrika U.G. (2007). Content and in vitro accessibility of pro-vitamin A carotenoids from Sri Lankan cooked non-leafy vegetables and their estimated contribution to vitamin A requirement. International Journal of food Science and Nutrition 58(8):659-667.

10. Priyadarshani A.M.B., Jansz E.R. \& Peiris H. (2006). An investigation of the carotenoids of Carica papaya. Vidyodaya Journal of Science. Submitted. 